\title{
Las Pozas (Casaseca de las Chanas, Zamora): dos nuevos recintos de fosos calcolíticos en el Valle del Duero
}

\author{
Las Pozas (Casaseca de las Chanas, Zamora): two new Copper Age causewayed enclosures \\ in the Douro Valley
}

Marcos García García $(*)$

\section{RESUMEN}

Desde 1975 el yacimiento de Las Pozas ha dado nombre al horizonte precampaniforme de la Submeseta Norte de la Península Ibérica. En la última década se han localizado varios recintos de fosos adscritos a este periodo que han motivado una revisión del yacimiento fundacional utilizando técnicas de teledetección. Las imágenes de infrarrojo han permitido distinguir en Las Pozas dos recintos de fosos superpuestos: el septentrional con tres líneas de foso y el meridional con dos. En este artículo se describen las características de ambos empleando la información revelada por las excavaciones de 1979 y 1987. Consideramos que el hallazgo certifica que este tipo de yacimientos no son una excepción en el Calcolítico del Valle del Duero.

\begin{abstract}
Since 1975 the site of Las Pozas has given its name to the prebeaker horizon in the Spanish Northern Plateau. In the last decade several causewayed enclosures dated to this period have been discovered. This new situation has led us to revise the foundation site using remote sensing techniques. The infrared images have allowed us to distinguish two overlapping enclosures at Las Pozas: a north one with three interrupted ditches and a southern group composed of two circles. This paper describes the characteristics of both enclosures using as well the information provided by the 1979 and 1987 excavations. We believe this discovery certifies that causewayed enclosures were a common feature in the Douro Valley during the Copper Age.
\end{abstract}

(*) Dpto. de Prehistoria y Arqueología. Universidad de Valladolid. Plaza del Campus s/n. 47011 Valladolid.

Correo e.: mggarcia@fyl.uva.es

Recibido 1-II-2012, aceptado 20-II-2012.
Palabras clave: Recintos de fosos segmentados; Hoyos; Submeseta Norte; Valle del Duero; Calcolítico; Teledetección espacial; Fotografía aérea; Imagen de infrarrojos; Sociedades complejas; Colonización agrícola.

Key words: Causewayed enclosures; Pits; Spanish Northern Plateau; Douro Valley; Copper Age; Spatial Remote Sensing; Aerial Photography; Infrared image; Complex societies; Agricultural colonization.

\section{INTRODUCCIÓN}

'Las Pozas' ha sido el epíteto del horizonte precampaniforme de la Submeseta Norte desde que las primeras prospecciones en este yacimiento zamorano devolvieron materiales que presentaban claros paralelismos con los de Vilanova de São Pedro en Portugal. Desde aquella definición el conocimiento que poseemos del Calcolítico del Valle del Duero se ha ampliado notablemente y, en los últimos 15 años, ha incorporado una novedad fundamental: los recintos de fosos. Identificados por primera vez en esta región a través de las fotografías aéreas de Julio del Olmo (1999), han sumado nuevos ejemplos (Ariño y Rodríguez 1997) hasta llegar a casi medio centenar, la mayoría aún inéditos. La prospección de algunos de estos recintos $\mathrm{y}$, sobre todo, la excavación de El Casetón de la Era II (Villalba de los Alcores, Valladolid) iniciada en agosto de 2006 han permitido constatar que fueron construidos durante la Edad del Cobre, en ocasiones con otra ocupación en la Edad del Bronce, una vez que los fosos estaban amortizados (Delibes et al. 2009: 245). Estos hallazgos suponen una auténtica revolución, pues se- 
rían las primeras estructuras de cierta envergadura en una zona que normalmente se supone ocupada por pastores seminómadas hasta la Primera Edad del Hierro (Delibes y Fernández 2000: 115).

En este marco de novedades se encuadra la noticia de la que nos ocupamos. El 'horizonte Las Pozas' no solo ha sumado a su elenco los recintos de fosos hallados en la región, sino que el propio yacimiento epónimo estuvo también circundado por los característicos anillos concéntricos. Un breve recordatorio de las aportaciones de este yacimiento a la arqueología regional dará cuenta de la importancia del descubrimiento.

\section{HISTORIA DE LAS INVESTIGACIONES EN LAS POZAS}

El yacimiento de Las Pozas se sitúa en el punto kilométrico 11,3 de la carretera autonómica CL-605 que une Casaseca de las Chanas $(2 \mathrm{~km}$ al NO) y Gema (1,1 km al SE), dos pueblos de la zamorana Tierra del Vino. En este entorno de llanura, el enclave ocupa una de sus suaves lomas (707 m.s.n.m.), $500 \mathrm{~m}$ al noroeste del Ariballos, arroyo tributario del Duero, de cuyas avenidas torrenciales le resguardan $30 \mathrm{~m}$ de desnivel (Fig. 1). Los suelos sobre los que tiene asiento Las Pozas son de calidad mediocre para el cultivo (calizas arenosas, areniscas calcáreas, margas y limonitas) por su elevado $\mathrm{pH}$ y pobreza en fósforo, si bien el vallejo del Ariballos ofrece tierras arenosas, más frescas y fértiles, a poca distancia del yacimiento.

Las primeras noticias del lugar proceden de la década de 1970, cuando R. Martín y G. Delibes (1972: 10-11) acompañaron al descubridor, N. Diego, en las primeras visitas al yacimiento. En ellas pudieron constatarse unos manchones cenicientos en los que se concentraban materiales de filiación calcolítica, similares a los conocidos en la Estremadura portuguesa (Martín y Delibes 1975: 451). La excavación de 1979 dirigida por Delibes, certificó que los manchones cenicientos correspondían a la destrucción por parte del arado de estructuras subterráneas, concretamente un 'silo' y parte de una zanja. La superficie exhumada se ampliaría en una segunda campaña dirigida por Jesús del Val en 1987. En ella se documentó 5 hoyos y dos partes de una zanja de longitud y disposición no precisadas, que tenía $4 \mathrm{~m}$ de

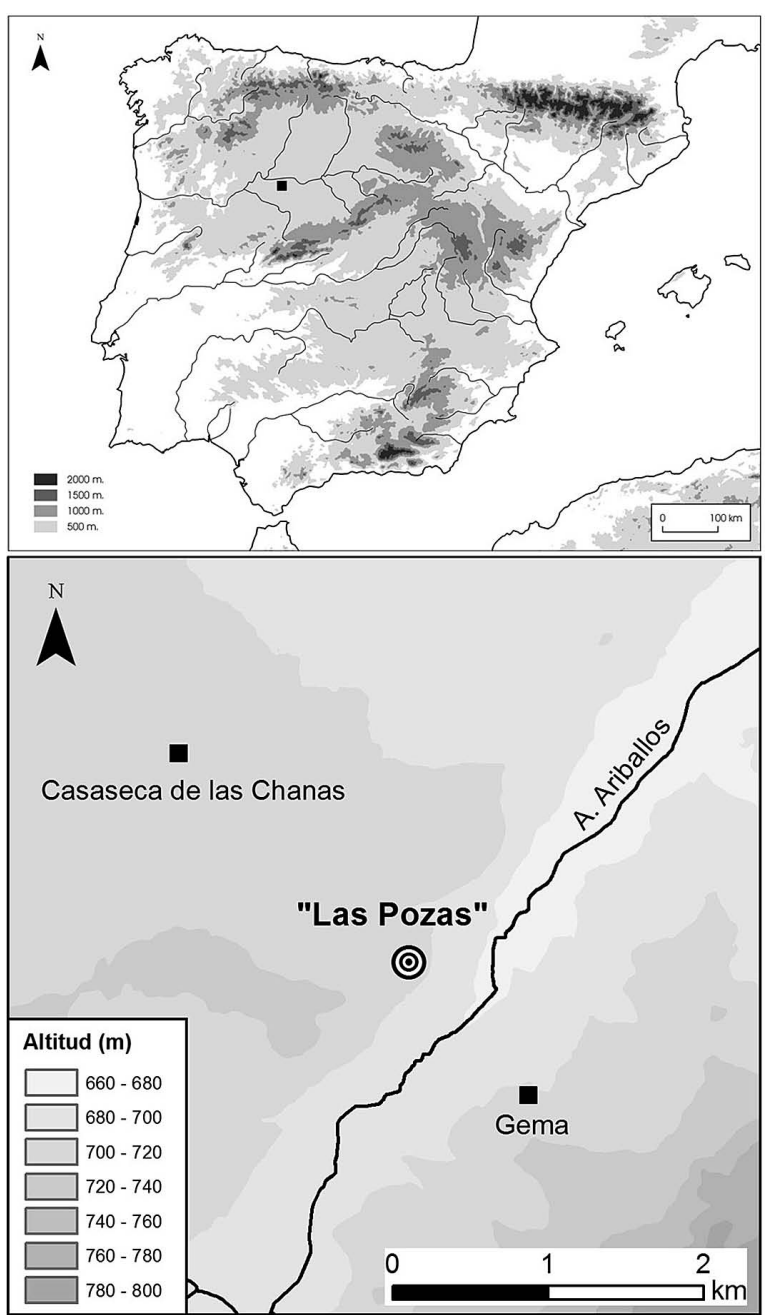

Fig. 1. Localización de Las Pozas (Casaseca de las Chanas, Zamora) en la Península Ibérica.

anchura y entre 1,79 y $2,15 \mathrm{~m}$ de profundidad en el punto en que fue cortada por la excavación (Val 1992) (1). Esta zanja, como los hoyos, fue colmatada con vertidos diversos (cenizas, barro, vestigios de fauna y abundantes restos de cultura material) que revelaban su utilización como muladar o basurero (Val 1992: 51).

(1) Este artículo resume la memoria de licenciatura de Jesús del Val 1983: El Calcolitico Precampaniforme en el Occidente de la Meseta. El yacimiento de 'Las Pozas (Zamora)', defendida en la Facultad de Filosofía y Letras de la Universidad de Valladolid (Valladolid). Dicha investigación se basa en la campaña dirigida por Delibes, a la que añade los datos de la que él mismo dirigió en 1987. 
Los restos permitieron completar el listado de fósiles del horizonte precampaniforme meseteño. Las cerámicas son de perfil esférico y carenado bicónico, rara vez decoradas (espigas, triángulos rellenos de puntos, meandros a peine, pastillas en relieve, oculados). Hay morillos de barro y molinos de granito. Dominan la industria lítica las hachas pulimentadas, las puntas de flecha y los elementos de hoz. Los objetos sobre hueso comprendían varillas, agujas, punzones $\mathrm{y}$, excepcionalmente, un botón de perforación en ' $V$ '. Los instrumentos de cobre, fabricados localmente a juzgar por la presencia de crisoles, representan el ejemplo más antiguo de metalurgia en el Valle del Duero (Val 1992: 52-56, figs. 4 y 5).

Las investigaciones devolvieron, además, dos fechas radiocarbónicas a partir de sendas muestras en el fondo de la zanja y en el nivel superior de colmatación. La primera $(\mathrm{GrN}-12126=4425$ $\pm 30 \mathrm{BP})$ situaría la fundación del lugar entre 3323-2923 cal ANE y la segunda (GrN-12127= $4075 \pm 30 \mathrm{BP}$ ) fecharía su clausura entre 28562493 cal ANE (2). La ocupación del yacimiento se produciría, entonces, en algún momento entre los últimos siglos del IV milenio y la mitad del III ANE.

Las Pozas no ha vuelto a ser inspeccionado con miras científicas desde entonces, pero sí había llamado la atención de ciertos investigadores la similitud de las estructuras exhumadas 20 años atrás con las que se estaban documentando en yacimientos con círculos concéntricos de otras partes de la Península Ibérica (Díazdel-Río 2001: 209). Solo era cuestión de tiempo revisar si las zanjas halladas en Casaseca de las Chanas eran parte también de un entramado de fosos. La falta de recursos económicos para una nueva excavación se vio compensada por una creciente curiosidad hacia los hitos fundacionales del Calcolítico meseteño conforme aumentaba la lista de recintos de fosos localizados con fotografía aérea. La pregunta de si Las Pozas fue también uno de ellos no hallaría respuesta removiendo la tierra, sino observando desde el cielo.

(2) La calibración se ha realizado con el programa OxCal 4.1 a $2 \sigma(95,4 \%$ de probabilidad $)$ a partir de las fechas publicadas por Val (1992: 59).

\section{METODOLOGÍA: TELEDETECCIÓN ESPACIAL}

La teledetección engloba las técnicas destinadas a informar sobre un objeto mediante un sensor a distancia. En nuestro estudio se emplea la cámara digital ADS80 del Plan Nacional de Ortofotografía Aérea (PNOA), promovido por el Instituto Geográfico Nacional (IGN) en colaboración con las Comunidades Autónomas. Gracias a este proyecto es posible trabajar con imágenes de toda la región, tomadas desde un ángulo de $90^{\circ}$ al suelo (3). Como todos los elementos poseen la misma escala es posible establecer su forma y dimensiones, ubicándolos correctamente en el espacio.

La base metodológica de nuestro trabajo radica en el crecimiento diferencial de los cultivos basado en la influencia de su coloración y altura sobre las estructuras subterráneas. Si las raíces coinciden con estructuras negativas, como los fosos y hoyos que nos ocupan, zonas de acumulación de humedad, el vegetal tenderá a madurar antes y a alcanzar una talla mayor (Wilson 1982: 55). Los cereales son especialmente sensibles a estas variaciones fácilmente visibles desde el aire entre la segunda mitad de mayo y finales de junio.

La fuente de información principal de este estudio ha sido una imagen de falso color del PNOA de 2007. Tiene $25 \mathrm{~cm}$ de resolución y se corresponde con la hoja 397-54 del Mapa Topográfico Nacional (escala 1:5.000). Fue tomada entre el 13 de marzo y el 8 de mayo de 2007. Se analizó mediante el programa ArcGis 9.3.1 de ESRI que permite ecualizar los histogramas según la extensión deseada. Al combinar los zooms con los aumentos de contraste, se observa con mayor nitidez los segmentos de foso y los hoyos en las parcelas 5 y 6 (Fig. 2A-C y Fig. 3A). En cambio, en las situadas al NE del camino que une Casaseca y Gema (50-52) es necesario recurrir a una imagen a color del PNOA de 2002. En los terrenos adyacentes el estado de los cultivos o la alteración del suelo producida por las labores de arada impiden distinguir estructura alguna.

La mayor dificultad del procedimiento radica en la discriminación de las estructuras prehistóri-

(3) La Junta de Castilla y León ofrece gratuitamente ortofotos en color e infrarrojo con una resolución espacial de $25 \mathrm{y}$ $50 \mathrm{~cm}$, y una resolución temporal de dos años: http://ftp.itacyl. es/cartografia/01_Ortografia (consulta 07-IV-2013). 


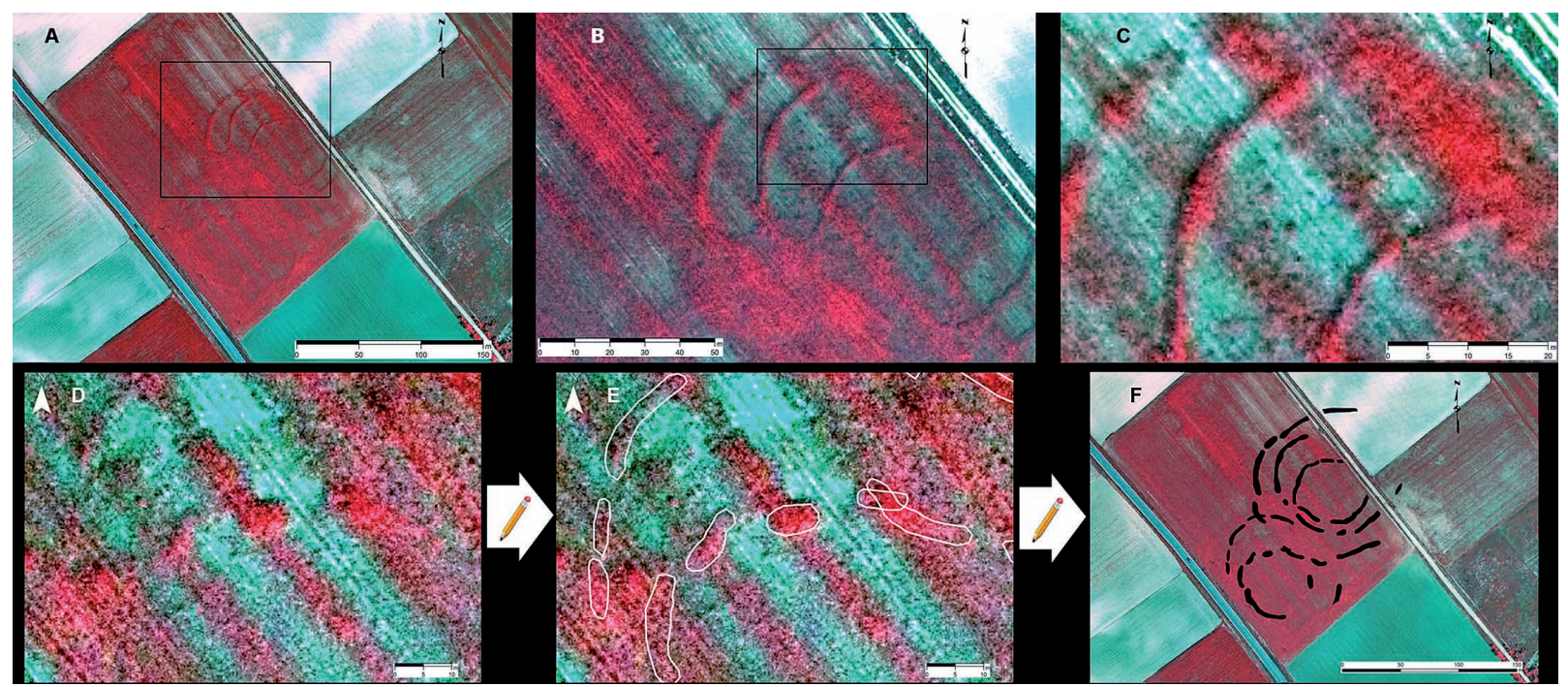

Fig. 2. Proceso de interpretación de la imagen de falso color del Plan Nacional de Ortofotografía Aérea (2007) correspondiente a la hoja 397-54 del Mapa Topográfico Nacional (escala 1:5.000): A. visión general del yacimiento de Las Pozas (Casaseca de las Chanas, Zamora); B. y C. amplían los recuadros marcados en A. y B., respectivamente, con el consiguiente aumento del contraste; D. y E. dibujo de la capa vectorial sobre los segmentos identificados; F. la capa vectorial finalizada sobre la ortofoto.

cas respecto a intrusiones como caminos antiguos, arroyos hoy encauzados, etc. Tras ese proceso las zanjas identificadas en la fotografía son dibujadas en una capa vectorial que 'limpia' la imagen de los fosos (Fig. 2D-F). Donde las estructuras no son visibles se ha prolongado el trazado del anillo para facilitar el cálculo de su perímetro, diámetro y extensión.

\section{DESCRIPCIÓN DE LAS ESTRUCTURAS}

\subsection{Los fosos}

El resultado de la interpretación de las imágenes del PNOA indica que la zanja excavada en 1979 y 1987 forma parte de un conjunto compuesto por dos recintos de fosos: uno septentrional formado por tres anillos y otro más meridional de doble línea. Ambos se cruzan en el centro del yacimiento (Fig. 3A). Son dos recintos muy similares entre sí (Fig. 4). Las dimensiones de los anillos menores son casi idénticas $(0,3 \mathrm{ha}) \mathrm{y}$ comparten una forma más o menos circular. Las demás líneas de foso tienden al óvalo como pue- de apreciarse en la diferencia entre sus ejes mayor y menor. La extensión del anillo intermedio del Recinto Norte y la del exterior del Recinto Sur coinciden (0,8 ha). Tampoco se aprecian grandes diferencias en la anchura superficial de los fosos (de 3,5 a 4,5 m) con la lógica precaución de que pueda estar afectada por otros factores. Los estrangulamientos y ensanchamientos que reducen y aumentan medio metro sus dimensiones no contradicen las de la zanja excavada (Val 1992: 50).

Matiza lo dicho anteriormente la relación entre el área encerrada por cada anillo y la superficie de los segmentos de foso correspondientes $\left(\mathrm{R}_{\mathrm{af}}\right.$ en Fig. 4). Se atestigua de nuevo las similitudes entre el anillo interno del Recinto Norte $\left(7 \mathrm{R}_{\mathrm{af}}\right)$ y el del Recinto Sur $\left(7,5 \mathrm{R}_{\mathrm{af}}\right)$. Observamos que la diferencia entre los círculos mediano y grande del Recinto Norte no es muy amplia, ya que el menor tamaño del intermedio se compensa con un menor espaciado entre segmentos. El cálculo de la superficie del anillo externo del Recinto Sur no depende tanto de los segmentos identificados como de su necesaria prolongación para cubrir las zonas sin foso al Sur (carretera) y NE (superposición del anillo norte). 


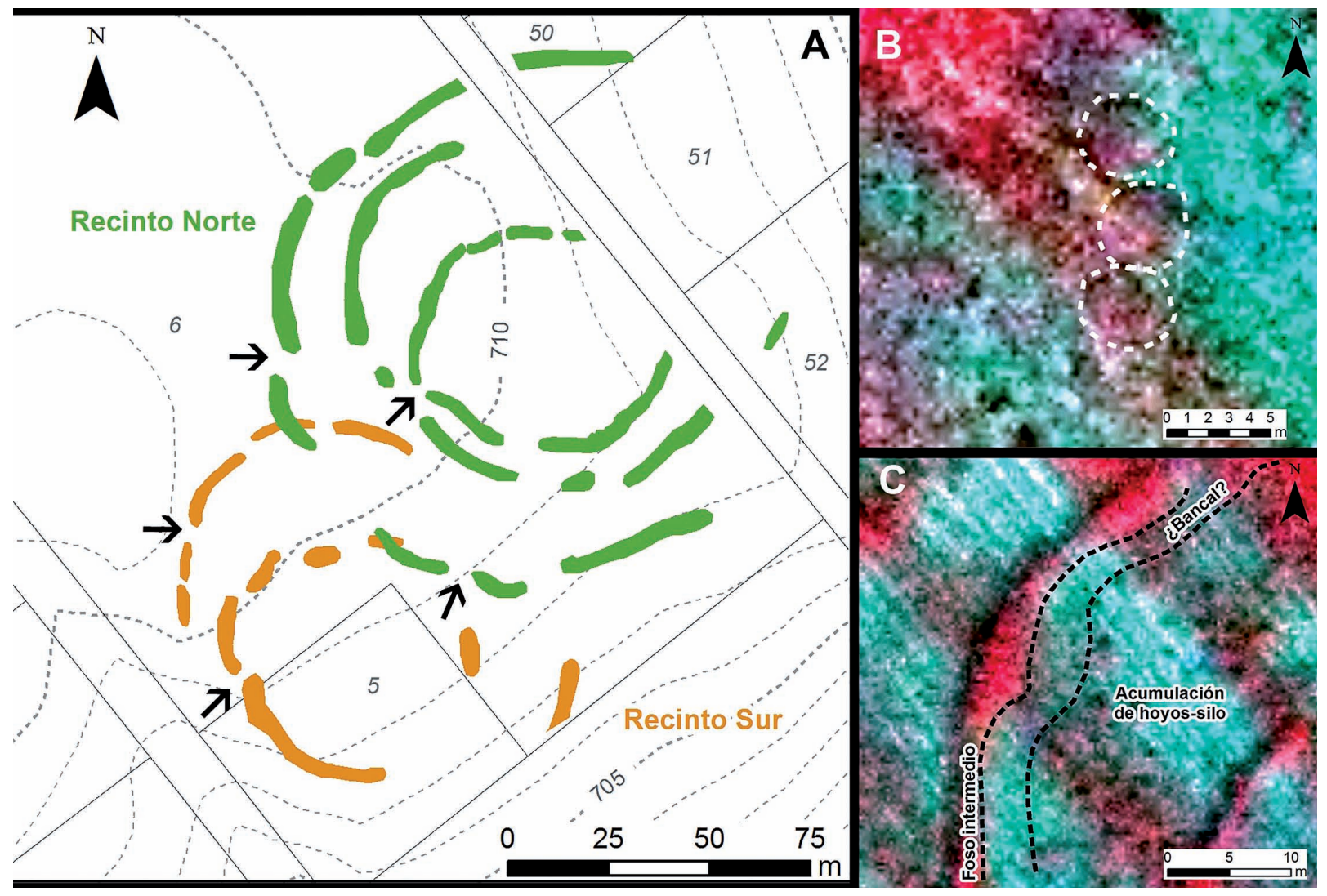

Fig. 3. Las Pozas (Casaseca de las Chanas, Zamora): A. interpretación del trazado de los fosos detectados sobre el parcelario (números en cursiva), curvas de nivel cada metro. Las flechas indican las posibles entradas. B. Círculos de gran tamaño en el centro del yacimiento que podrían corresponder a cabañas; C. espacio entre un grupo de hoyos y el foso intermedio del Recinto Norte, donde pudo existir un bancal de tierra.

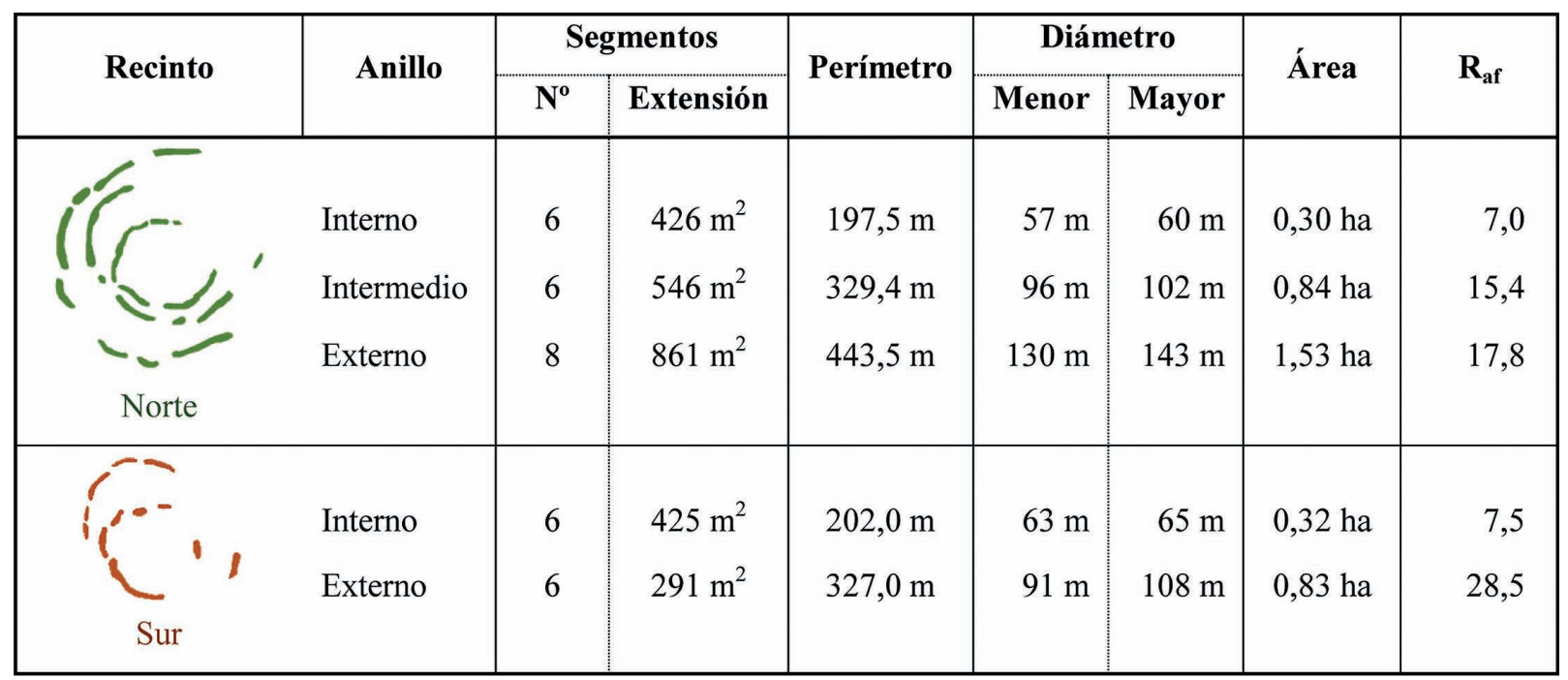

Fig. 4. Comparación de las dataciones absolutas calibradas de Las Pozas (Val 1992: 59) y El Casetón de la Era II (Delibes 2011: 17). La calibración se ha realizado con el programa OxCal 4.1 a $2 \sigma$. 
Las interrupciones en la línea de foso son comunes en lo que se ha denominado la "segunda generación de recintos" correspondiente a los recintos europeos del IV milenio ANE (Márquez y Jiménez 2010: 310-313), entre ellos los causewayed enclosures británicos (Oswald et al. 2001: 1, 49) y los ejemplos publicados de la Submeseta Norte (Ariño y Rodríguez 1997; Olmo 1999). Ante esta imagen de fosos segmentados se tiene siempre la tentación de juzgar los espacios como entradas al interior del recinto. El asunto, a nuestro juicio, debería tomarse con mucha precaución, ya que no contamos con la seguridad de que los fosos que observamos hoy fuesen la única estructura que circundaba los yacimientos. En varios casos se han documentado taludes de tierra delante y/o detrás de los fosos con un desarrollo más continuo que el de estos (Oswald et al. 2001: figs. 3.1 y 3.20). Lamentablemente, estas estructuras son muy susceptibles de desaparecer por procesos postdeposicionales como la acción del arado (Oswald et al. 2001: fig. 3.9).

En Las Pozas, la excavación no ha permitido verificar la existencia de estas estructuras por lo que debe recurrirse a la fotografía aérea. En la imagen se aprecia una situación idéntica a la detectada en Perdigões por prospección geomagnética (Márquez et al. 2011: 183): un vacío a modo de corona entre el moteado de hoyos y los fosos que podría corresponder a alguna estructura circundante desaparecida (Fig. 3C). Los escasos hoyos superpuestos no contradicen la hipótesis, puesto que la excavación certificó que eran anteriores a los fosos (Val 1992: 50-51 y fig. 2).

Con estas premisas y con todas las precauciones, consideramos que en Las Pozas no todos los espacios entre segmentos fueron entradas al recinto. Coincidimos con las conclusiones del análisis morfológico de varios causewayed enclosures según el cual las líneas poseían una entrada o, en el caso más extremo, cinco (Oswald et al. 2001: 49). Para localizar las posibles entradas debe buscarse algún elemento distintivo dimensional o formal. En ambos recintos hay vanos de medidas muy llamativas: uno de 8 a $10 \mathrm{~m}$ en los tres anillos del Recinto Norte en su parte meridional, otro de 26 $\mathrm{m}$ al SO de su círculo exterior y un tercero de 63 $\mathrm{m}$ al NE del anillo exterior del Recinto Sur. Ante estos datos, el argumento del tamaño no resulta muy convincente, puesto que los tres ejemplos coinciden con la superposición de ambos recintos.
Por ello nos inclinamos más bien a considerar que las entradas estuvieron marcadas por una forma acorde con los dos diseños establecidos en el estudio sobre los enclosures ingleses: curvando el segmento de foso (hacia el interior preferentemente) o alargándolo por encima del desarrollo anular (Oswald et al. 2001: fig. 3.18 y fig. 3.19). En Las Pozas se detectan varios segmentos de foso curvados hacia el interior que pudieron marcar varias entradas: una al SO de cada uno de los anillos internos de ambos recintos, dos en el foso exterior del Recinto Norte (al Oeste y al Sur) y otra al NO del anillo mayor del Recinto Sur (Fig. 3A). Aventuramos que la entrada al foso intermedio del Recinto Norte continuaba la del anillo interior, coincidiendo con una acumulación de hoyos de gran tamaño que distorsiona la forma del anillo.

\subsection{Los hoyos y cabañas}

El moteado que inunda la fotografía es el otro elemento conservado en cualquier recinto de fosos. Su distribución no es homogénea. Se presenta en coronas a cierta distancia del foso (Fig. 3C), formando cúmulos o, con menor frecuencia, sobre la misma línea de foso.

El tamaño de las estructuras es igualmente heterogéneo. Lo agrupamos en dos tipos. El primero respondería a la morfología de hoyos siliformes (circulares con un diámetro de 1,5 m). Son idénticos a los cinco excavados con fondo plano y una profundidad que variaba entre los $2,1 \mathrm{~m}$ de los hoyos del interior del foso y los $1,2 \mathrm{~m}$ de los que estaban en las paredes del mismo. $\mathrm{Su}$ función resulta como siempre controvertida. $\mathrm{Su}$ relleno (cenizas, fragmentos cerámicos, de fauna y de barro de construcción) animó a considerarlos basureros o, a partir de los restos de bóvido en conexión anatómica localizados en dos hoyos, como lugares de almacenamiento de alimentos (Val 1992: 50). Esta deposición de animales en estructuras subterráneas se registra también en otras 10 estaciones calcolíticas del Duero Medio (Bellido 1996: 46; García 2008: 192), incluyendo El Casetón de la Era II (Delibes et al. 2009: 249). Se trata de una práctica generalizada desde el Calcolítico a la Edad del Bronce (Liesau y Blasco 2006: 86-87) con especial fijación por bóvidos y cánidos que cuenta con multitud de ejemplos 
peninsulares (Díaz-del-Río 2001: 200-202 y lám. 12; Liesau et al. 2008: 106-108; Márquez y Jiménez 2010: 219-224). Estos depósitos se han interpretado como parte de festines asociados a ritos de tránsito, demostraciones de riqueza al estilo potlatch o marcas de memoria grupal en visitas recurrentes (4). Lo más probable es que la variedad de formas y depósitos que observamos hoy resulte de procesos diferentes, con estructuras que se excavaron con una función que dejó de tener sentido tiempo después.

El segundo tipo de estructura corresponde a círculos de entre 3 y $4 \mathrm{~m}$ de diámetro. No están afectados por las excavaciones arqueológicas, pero son fácilmente reconocibles en la ortofoto: un grupo siguiendo el lado oriental del foso interno del Recinto Norte y otro en el sector central del yacimiento, donde se superponen los dos recintos (Fig. 3B). Teniendo en cuenta el tamaño de estos círculos pensamos que pueden corresponder a pequeñas cabañas como las documentadas recientemente en El Casetón de la Era II (Delibes 2011: 15).

\subsection{Cronología de los recintos}

La interpretación de los recintos debe considerar su temporalidad, esto es, entender que las estructuras que estudiamos son resultado de la acumulación de procesos de construcción, remodelación y destrucción que aún hoy continúan. Discernir esta historia interna del recinto permitiría precisar el tamaño del yacimiento o la posible estabilidad de la ocupación (Márquez y Jiménez 2010: 372). Dentro de esta problemática, surge la pregunta de si los dos recintos de Las Pozas fueron contemporáneos. El solapamiento de dos segmentos de sus respectivos anillos en el sector central, las diferencias en el diseño y, sobre todo, el vacío existente en la zona central donde los recintos se superponen, ilustran la fosilización de uno por otro (Fig. 3A).

Es difícil asegurar cuál es el más antiguo ya que ha resultado imposible certificar a qué recinto corresponde la zanja excavada parcialmente en

(4) La bibliografía específica de las diferentes propuestas puede consultarse en Márquez y Fernández (2002: 318-319). Sobre la controvertida función de los hoyos recomendamos el trabajo de Márquez y Jiménez (2010: 346-362).
1979 y 1987 (5), pero sí podemos afirmar que se trazó tras una primera ocupación del yacimiento representada por los cinco hoyos documentados. Estaríamos en condiciones de fechar ese momento pues entre los valiosos datos que han devuelto las intervenciones arqueológicas, se cuenta una tercera datación procedente del fondo de un hoyo más antiguo que la zanja (GrN-12125). La fecha 4425 \pm 35 BP (3327-2922 cal ANE) (6) es idéntica a la de la fundación del foso que lo corta (33232923 cal ANE), lo que indica que apenas medió tiempo entre la primera ocupación de Las Pozas y la construcción del foso (Fig. 5).

\section{DISCUSIÓN: LOS RECINTOS DE FOSOS Y LA INAUGURACIÓN DE LA VIDA SEDENTARIA}

Los nuevos datos que aporta hoy Las Pozas son en realidad antiguos pues debe considerarse como el primer recinto de fosos del Valle del Duero objeto de una excavación. Su revisión viene a coincidir con lo que empezamos a conocer en El Casetón de la Era II y nos anima a ver en estos recintos el inicio de un proceso de sedentarización en la Meseta.

Obviamente es aventurado extraer conclusiones sobre la funcionalidad de los recintos de fosos sin tener publicados los demás casos. Ello no impide resaltar la paradoja que supone la investigación de Las Pozas: el yacimiento, aceptado desde 1979 como paradigma de los poblados del Valle Medio del Duero, podría ser objeto de polémica al constatarse en él la presencia de zanjas concéntricas. Cabe preguntarse hasta qué punto la detección de estas estructuras desdice el registro documentado hace 30 años para las corrientes que atribuyen una función monumental a este tipo de yacimientos. Más bien creemos que lo que se plantea en el recinto zamorano es un problema común al Calcolítico de la Meseta: la dificultad de establecer como definitivo cualquier argumento referido a las nociones 'hábitat' $\mathrm{o}$, más aún, 'estable' antes

(5) Los responsables de las excavaciones de 1979 y 1987 nos han comunicado que, lamentablemente, falta la planimetría general del yacimiento. La imagen aérea permite aventurar cierta similitud entre la porción exhumada (Val 1992: fig. 2) y los segmentos del anillo intermedio del Recinto Norte sin poder ir más lejos.

(6) Véase n.2.

Trab. Prehist., 70, N. ${ }^{\circ}$ 1, enero-junio 2013, pp 175-184, ISSN: 0082-5638 doi: $10.3989 /$ tp.2013.12108 


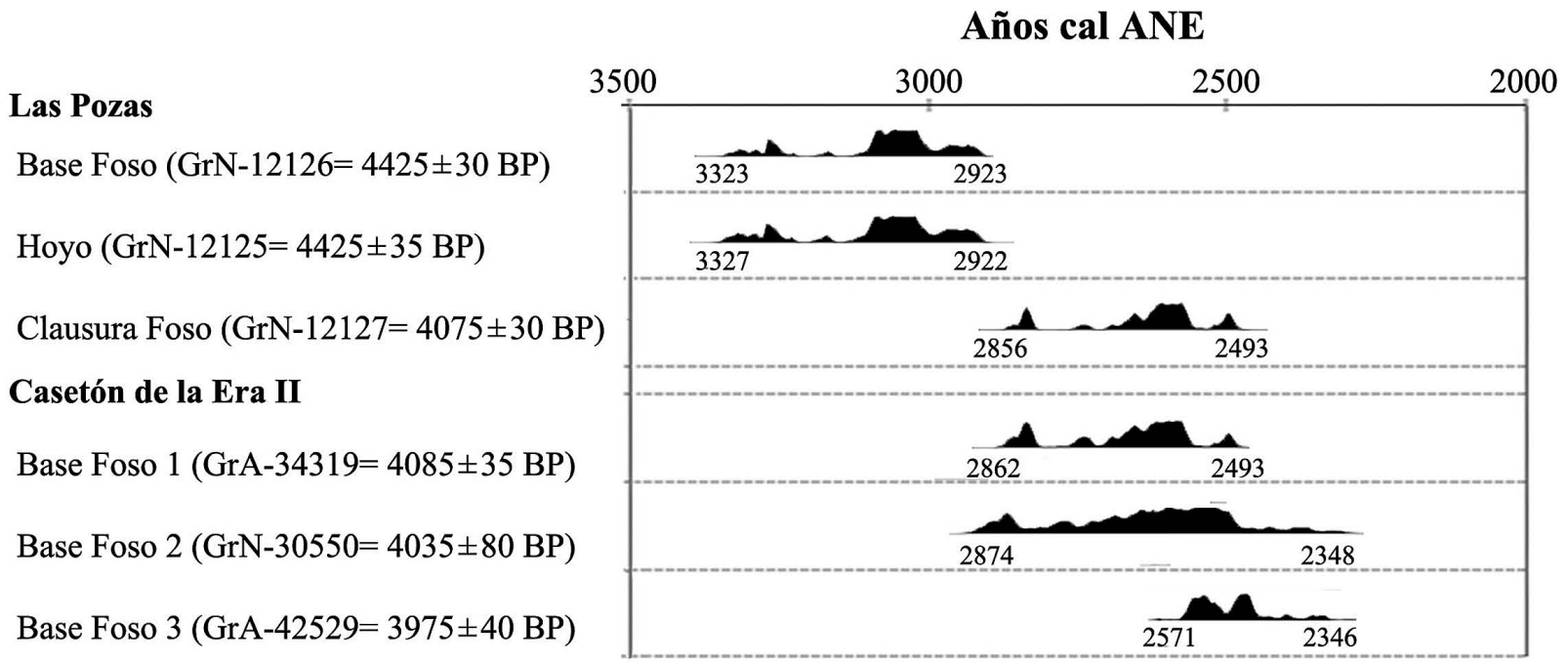

Fig. 5. Dimensiones de los fosos de Las Pozas (Casaseca de las Chanas, Zamora). La columna $\mathrm{R}_{\mathrm{af}}$ corresponde a la relación entre el área que encierra cada anillo y la extensión de los segmentos de foso.

de la Edad del Hierro. En cualquier caso, dicha problemática no debe desanimar el resumen de las evidencias de ocupación reunidas en Las Pozas. Insistimos en nuestra intención de evitar de momento el debate 'monumento-poblado', por más que los siguientes párrafos evidencien la existencia del mismo.

Las Pozas concentró desde las primeras excavaciones una serie de argumentos sobre su condición de poblado. En primer lugar, existen evidencias de actividad agrícola estable, como los útiles de hoz con lustre de cereal o la cercanía a suelos apropiados para una agricultura intensiva que suponen un $17 \%$ del terreno incluido en un radio de $1 \mathrm{~km}$ en torno al yacimiento (7). El segundo testimonio a favor de la sedentarización sería el peso del ganado en la alimentación: el $75 \%$ de los restos animales recuperados pertenecen a especies domésticas, siendo mayoritarios los ovicápridos (34\%), los bóvidos (28\%) y los suidos

(7) La cifra proviene de un análisis locacional que recrea los usos potenciales del suelo en condiciones paleotécnicas y que es parte de nuestro libro Los recintos de fosos prehistóricos del Duero medio. Arqueología Aérea y Espacial escrito con la colaboración de G. Delibes, J. de Santiago y J. del Olmo (e.p.). Para ello se han utilizado factores como la pendiente del terreno, el drenaje, la permeabilidad, la distancia a fuentes de agua y el sustrato edafológico. Los suelos de uso agrícola extensivo supondrían un $79 \%$.
$(12 \%)$. Las edades de sacrificio son elevadas en el caso de los dos primeros, lo que señala que su objetivo era conseguir "productos secundarios" como la leche (se han documentado queseras, Val 1992: fig. 4), el abono o la fuerza de tiro (8). A esto debe sumarse que el ganado porcino, mucho menos móvil, se sacrificaba a edades más tempranas $\mathrm{y}$, al parecer, siempre en la misma época del año (Morales 1992: 84). Un tercer argumento lo constituye la complejidad de excavar los fosos que, aun no siendo contemporáneos, supusieron la remoción de unos $5000 \mathrm{~m}^{3}$ de arenas compactas y greda (9). Un cuarto elemento para apoyar esta hipótesis son los restos constructivos de barro con improntas vegetales. Forman parte del relleno del foso y de algunos hoyos y podrían provenir de estructuras aéreas de ramaje, seguramente las posibles cabañas localizadas en la fotografía aérea. Además abundan los objetos 'domésticos' (cerá-

(8) Así lo demuestra el reciente descubrimiento de piedras de trillo en el Casetón de la Era II. La forma de estas no difiere de los elementos de hoz hallados en Las Pozas, pero los análisis traceológicos han revelado que su función era diferente a la mantenida hasta hoy, lo que a su vez es una clara práctica de agricultura estable (Gibaja et al. 2012).

(9) El cálculo corresponde a un foso de sección ' $V$ ' usando la superficie de los segmentos de foso conocidos $\left(2.549 \mathrm{~m}^{2}\right)$ y una profundidad de $2 \mathrm{~m}$, que sería la media de las máximas observadas en excavación (1, 79 m y 2,15 m) según Val (1992: 50-51). 
micas, molinos de mano, morillos). El último argumento son las dataciones absolutas que, a pesar de la incertidumbre del método, indican eventos de ocupación separados casi 500 años (Fig. 5). El lapso puede ser resultado de visitas intermitentes, pero nos inclinamos por interpretarlo como una larga ocupación del yacimiento a la luz de las demás evidencias comentadas.

Por su parte, las últimas investigaciones en El Casetón de la Era II dibujan un escenario similar (Delibes 2011: 15-26), siendo de esperar que próximas publicaciones incidan en el carácter habitacional de los dos recintos de fosos mejor conocidos de la Submeseta Norte.

\section{CONCLUSIONES}

El hallazgo de Las Pozas es un paso más en la generalización de un fenómeno que hasta hace unos años era una excepción en la cuenca del Duero. El 'horizonte Las Pozas' tiene en los recintos de fosos el ejemplo más evidente del cambio social que se produjo en la Meseta a finales del IV milenio ANE en un contexto de colonización agrícola. Pequeños grupos humanos fundaron estos poblados rodeados de fosos en las tierras sedimentarias de la Meseta, un medio con buenas condiciones para una vida campesina. Aparecen así las primeras sociedades con signos evidentes de complejidad en esta región: especialización del trabajo (agricultores, ganaderos, metalúrgicos), intercambios a media distancia (10), cohesión grupal ritualizada (depósitos de animales) y un liderazgo organizativo que permitió la ejecución de obras cooperativas. Es difícil concluir, a partir del registro disponible, si la ocupación fue continua o estacional, de un único grupo o de la agregación temporal de varios. Pero a la inversa, carecemos de evidencias suficientes que nos hagan pensar en un carácter meramente ceremonial para los dos recintos citados, máxime cuando se desconoce otro tipo de yacimientos que contengan pruebas más claras de hábitat en la zona.

La construcción de recintos de fosos en la Península Ibérica se generaliza entre 3400 y 2300 ANE. Las Pozas se convierte así en uno de los

(10) Solo así se explica la presencia del sílex proveniente del páramo de los Torozos, $100 \mathrm{~km}$ al Este. ejemplos peninsulares más antiguos de la llamada "segunda generación de recintos" (Márquez y Jiménez 2010: 310-313) junto al onubense de Papa Uvas (3362-2930 cal ANE) (11), el alicantino de Niuet (3370-2910 cal ANE) o el madrileño de Gózquez (3355-2580 cal ANE). Curiosamente las dataciones disponibles (Díaz-del-Río 2001: fig. 41) se agrupan en torno a dos momentos amplios por la incertidumbre inherente al método: 34002800 ANE y 2800-2300 ANE. A pesar de este inconveniente resultan muy representativos en el caso del Valle del Duero: durante el primero se funda Las Pozas mientras que, entre las fechas del segundo, se clausura el recinto zamorano y se construye El Casetón de la Era II (Fig. 5). La colmatación de sus fosos hacia 2300 ANE coincide con un languidecimiento del fenómeno de los recintos (Liesau et al. 2008; Márquez y Jiménez 2010: 313-315) pero sin sepultar unas formas de vida que florecerán durante el Campaniforme.

\section{AGRADECIMIENTOS}

El trabajo aquí presentado está financiado por una beca de investigación de la Fundación del Patrimonio Histórico de Castilla y León (20112013). La idea de revisar el yacimiento zamorano me fue propuesta por Germán Delibes, al que agradezco que me guiase con la amabilidad y buen hacer que le caracterizan. Finalmente, este estudio es deudor de la dedicación de arqueólogos como Jesús del Val, José I. Herrán y Ricardo Martín a los que extiendo el agradecimiento por su incansable labor.

\section{BIBLIOGRAFÍA}

Ariño, E. y Rodríguez, J. 1997: "El poblamiento romano y visigodo en el territorio de Salamanca: datos de una prospección intensiva". Zephyrus 50: 225-245.

Bellido, A. 1996: Los campos de hoyos: inicios de la economía agrícola en la Submeseta norte. Studia Archaeologica 85, Universidad de Valladolid. Valladolid. Chuvieco, E. 2010: Teledetección Ambiental. La observación de la Tierra desde el espacio. Ariel. Madrid.

(11) Para la fase IV según Márquez y Jiménez (2010: tab. 02).

Trab. Prehist., 70, N. ${ }^{\circ}$ 1, enero-junio 2013, pp 175-184, ISSN: 0082-5638 doi: $10.3989 /$ tp.2013.12108 
Delibes, G. 2011: El pan y la sal. La vida campesina en el valle medio del Duero hace cinco mil años. Real Academia de Bellas Artes de la Purísima Concepción de Valladolid. Valladolid. http:// www.realacademiaconcepcion.net/ publicaciones/ rabapcd2011.pdf (consulta 07/IV/2013).

Delibes, G.; Crespo, M.; Fernández, J.; Herrán, J. I. y Rodríguez, J. A. 2009: "Un recinto de fosos calcolítico en el valle medio del Duero: El Casetón de la Era (Villalba de los Alcores, Valladolid)". En Actas de las IV Jornadas Cientificas de Patrimonio Arqueológico en la Comunidad de Madrid (Madrid 2007): 241-250. Madrid.

Delibes, G. y Fernández, J. 2000: "La trayectoria de la Prehistoria Reciente (6400-2500 BP) en la Submeseta Norte española: principales hitos de un proceso". En V. Oliveira Jorge (ed.): Actas do $3^{\circ}$ Congresso de Arqueologia Peninsular IV (Vila Real, Portugal 1996): 95-122. Porto.

Díaz-del-Río, P. 2001: La formación del paisaje agrario. Madrid en el III y II milenios BC. Arqueología, Paleontología y Etnografía 9, Comunidad de Madrid. Madrid.

García, Á. S. 2008: "El mundo ritual en la Prehistoria Reciente: una reflexión a propósito del caso de 'Los Cercados' (Mucientes, Valladolid)". Actas de las I Jornadas de Jóvenes en Investigación Arqueológica: dialogando con la cultura material I (Madrid 2008): 191-198. Madrid.

Gibaja, J. F.; Crespo, M.; Delibes, G.; Fernández, J.; Fraile, C.; Herrán, J. I.; Palomo, A. y Rodríguez J. A. 2012: "El uso de trillos durante la Edad del Cobre en la Meseta española. Análisis traceológico de una colección de denticulados de sílex procedentes del 'recinto de fosos' de El Casetón de la Era (Villalba de los Alcores, Valladolid)". Trabajos de Prehistoria 69 (1): 133-148.

Liesau, C. y Blasco, M. C. 2006: “Depósitos con fauna en yacimientos del Bronce Medio en la Cuenca del Tajo". En N. Ferreira (ed.): Animais na Pré-história e Arqueologia da Península Ibérica. Actas do IV Congresso de Arqueología Penínsular 3 (Faro, Portugal 2004): 81-92. Faro.
Liesau C.; Blasco, M. C.; Ríos, P.; Vega, J.; Menduiña, R.; Blanco, J. F.; Baena, F. J.; Herrera, T.; Petri, A. y Gómez, J. L. 2008: “Un espacio compartido por vivos y muertos: el poblado calcolítico de fosos de Camino de las Yeseras (San Fernando de Henares, Madrid)". Complutum 19 (1): 97-120.

Márquez, J. E. y Fernández, J. 2002: "Viejos depósitos, nuevas interpretaciones: la estructura $\mathrm{n}^{\circ} 2$ del yacimiento prehistórico de los Villares de Algane (Coín, Málaga)”. Mainake XXIV: 302-333.

Márquez, J. E. y Jiménez, V. 2010: Recintos de fosos: genealogía y significado de una tradición en la Prehistoria del suroeste de la Península Ibérica (IV-III milenios AC). Servicio de Publicaciones de la Universidad de Málaga. Málaga.

Márquez, J. E.; Valera, A. C.; Becker, H.; Jiménez, V. y Suárez, J. 2011: "El Complexo Arqueológico dos Perdigões (Reguengos de Monsaraz, Portugal). Prospecciones Geofísicas - Campañas 2008-09". Trabajos de Prehistoria 68 (1): 175-186.

Martín, R. y Delibes, G. 1972: "Nuevos yacimientos de la primera Edad del Hierro en la Meseta Norte". Boletín del Seminario de Estudios de Arte y Arqueología XXXVIII: 5-54.

Martín, R. y Delibes, G. 1975: "Hallazgos arqueológicos en la provincia de Zamora (II)". Boletín del Seminario de Estudios de Arte y Arqueología XLXLI: 445-476.

Morales, A. 1992: "Estudio de la fauna del yacimiento calcolítico de 'Las Pozas' (Casaseca de las Chanas, Zamora). Campaña 1979”. Boletín del Seminario de Estudios de Arte y Arqueología LVIII: 66-96.

Olmo, J. 1999: “Arqueología aérea en Castilla y León”. Revista de Arqueología 215: 44-99.

Oswald, A.; Dyer, C. y Barber, M. 2001: The Creation of Monuments. Neolithic Causewayed Enclosures in the British Isles. English Heritage. Swindon.

Val, J. 1992: "El yacimiento calcolítico precampaniforme de Las Pozas, Casaseca de las Chanas, Zamora". Boletín del Seminario de Estudios de Arte y Arqueología LVIII: 47-63.

Wilson, D. R. 1982: Air Photo Interpretation for Archaeologists. Batsford. Londres. 
TRABAJOS DE PREHISTORIA, 70 (1), 2013

ISSN: 0082-5638

eISSN: 1988-3218

FE DE ERRATAS:

Volumen 70, Número 1, 2013:

Marcos García García. Las Pozas (Casaseca de las Chanas, Zamora): dos nuevos recintos de fosos calcolíticos en el Valle del Duero

Los pies de las figs. 4 (p. 179) y 5 (p. 182) están intercambiados. 